University of Nebraska - Lincoln

DigitalCommons@University of Nebraska - Lincoln

Faculty Publications from the Harold W. Manter Laboratory of Parasitology

Parasitology, Harold W. Manter Laboratory of

$2-2000$

\title{
A Phylogenetic Hypothesis for Species of the Genus Taenia (Eucestoda: Taeniidae)
}

\author{
Eric P. Hoberg \\ United States Department of Agriculture, eric.hoberg@ars.usda.gov \\ Arlene Jones \\ Natural History Museum (London) \\ Robert L. Rausch \\ University of Washington, rausch@uw.edu \\ Keeseon S. Eom \\ Chungbuk National University \\ Scott Lyell Gardner \\ University of Nebraska - Lincoln, slg@unl.edu
}

Follow this and additional works at: https://digitalcommons.unl.edu/parasitologyfacpubs

Part of the Biodiversity Commons, Ecology and Evolutionary Biology Commons, and the Parasitology

Commons

Hoberg, Eric P.; Jones, Arlene; Rausch, Robert L.; Eom, Keeseon S.; and Gardner, Scott Lyell, "A Phylogenetic Hypothesis for Species of the Genus Taenia (Eucestoda: Taeniidae)" (2000). Faculty Publications from the Harold W. Manter Laboratory of Parasitology. 333.

https://digitalcommons.unl.edu/parasitologyfacpubs/333

This Article is brought to you for free and open access by the Parasitology, Harold W. Manter Laboratory of at DigitalCommons@University of Nebraska - Lincoln. It has been accepted for inclusion in Faculty Publications from the Harold W. Manter Laboratory of Parasitology by an authorized administrator of DigitalCommons@University of Nebraska - Lincoln. 


\title{
A PHYLOGENETIC HYPOTHESIS FOR SPECIES OF THE GENUS TAENIA (EUCESTODA: TAENIIDAE)
}

\author{
Eric P. Hoberg, Arlene Jones ${ }^{\star}$, Robert L. Rausch†, Keeseon S. Eom‡, and S. L. Gardner§ \\ United States Department of Agriculture, Agricultural Research Service, Biosystematics and National Parasite Collection Unit, \\ BARC East No. 1180, 10300 Baltimore Avenue, Beltsville, Maryland 20705
}

\begin{abstract}
Cladistic analysis of a numerical data matrix describing 27 characters for species of Taenia resulted in 4 most parsimonious phylogenetic trees ( 174 steps; consistency index $=0.28$; homoplasy index $=0.72$; retention index $=0.48$ ). Monophyly for Taenia is diagnosed by the metacestode that is either a cysticercus or a form derived from a bladder-like larva; no other unequivocal synapomorphies are evident. Tree structure provides no support for recognition of a diversity of tribes or genera within the Taeniinae: Fimbriotaeniini and Taeniini have no phylogenetic basis. Hydatigera, Fimbriotaenia, Fossor, Monordotaenia, Multiceps, Taeniarhynchus, Tetratirotaenia must be subsumed within Taenia as synonyms. Taenia saginata and Taenia asiatica are sister species and distantly related to Taenia solium. Cospeciation with respect to carnivorous definitive hosts and Taenia appears to be limited. Although felids are putative ancestral hosts, contemporary associations appear to have resulted from extensive host-switching among felids, canids, hyaenids, and others. In contrast, relationships with herbivorous intermediate hosts are indicative of more pervasive coevolution; rodents as intermediate hosts are postulated as ancestral for the Taeniidae, Taenia + Echinococcus. Patterns appear consistent with rapid shifts between phylogenetically unrelated carnivores but among those that historically exploited a common prey resource within communities in specific biogeographic regions.
\end{abstract}

Cestodes of the genus Taenia Linnaeus, 1758 are of considerable medical and veterinary significance and, as a consequence studies at the species-level, have been focused and intensive (e.g., Abuladze, 1964; Verster, 1969; Rausch, 1994, 1997). There have been in excess of 70 nominal species described in the genus (Verster, 1969), but morphological limits among species are often problematic. Currently, approximately 35-40 species are recognized based on adult specimens, including those validated by Verster (1969) and additional species that were subsequently described (e.g., Jones and Khalil, 1984; Jones et al., 1988; Eom and Rim, 1993); many species continue to be established for metacestodes (e.g., Murai et al., 1993).

Although considerable taxonomic revision has been conducted, disagreements continue over both the number of genera in the family (2-13) and the number of species that are valid within Taenia, e.g., compare Abuladze (1964), Movsessian (1989), Bessonov et al. (1994), and Spasskii (1998) with Verster (1969), Schmidt (1986), and Rausch (1994). At 1 extreme of this continuum, the taxonomy proposed by Abuladze (1964) and adopted with some modifications by Bessonov et al. (1994) recognized 2 subfamilies with 12 or 13 genera: (1) Taeniinae Stiles, 1896 for Taenia, Taeniarhynchus Weinland, 1758, Multiceps Goeze, 1782, Hydatigera Lamarck, 1816, Fossor Honess, 1937, Anoplotaenia Beddard, 1912, Insinuarotaenia Spasskii, 1948, Tetratirotaenia Abuladze, 1964, Cladotaenia Cohn, 1901 and Paracladotaenia Yamaguti, 1935; and (2) Echinococcinae Abuladze, 1960 for Echinococcus Rudolphi, 1801 and Alveococcus Abuladze, 1960. Taeniinae was partitioned into genera along 2 major ontogenetic paths; possession of fluid-filled metacestodes characterized Taenia, Hydatigera, Multiceps, and Tae-

Received 29 March 1999; revised 30 July 1999; accepted 30 July 1999.

* Department of Zoology, The Natural History Museum, Cromwell Road, London, SW7 5BD, U.K.

† Department of Comparative Medicine, School of Medicine, University of Washington, Box 357190, Seattle, Washington, 98195.

$\ddagger$ Department of Parasitology, College of Medicine, Chungbuk National University, Chongju 360-763, Korea.

$\S$ Harold W. Manter Laboratory of Parasitology, Nebraska State Museum, University of Nebraska-Lincoln, Lincoln, Nebraska 685880514 . niarhynchus; whereas a solid-bodied larva or armathyridium was regarded as typical of metacestodes in Cladotaenia and Tetratirotaenia. Subsequently, Fimbriotaenia Korniushin and Sharpilo, 1986 was established for a unique, fimbriocercus larval form characteristic of a limited number of species formerly referred to Taenia (Korniushin and Sharpilo, 1986).

In a further modification of this taxonomic framework, Spasskii (1998) recognized Taeniinae, Echinococcinae, and Anoplotaeniinae Spasskii, 1990. In Taeniinae, he diagnosed 2 tribes: (1) Taeniini Rosmassler, 1832, for forms with a reticulate vitellarium, including Taenia, Hydatigera, Multiceps, and Taeniarhynchus; and (2) Fimbriotaeniini Spasskii, 1996 in which the vitellarium was compact or lobed, including Fimbriotaenia, Insinuarotaenia, Monordotaenia Little, 1967 and Paracladotaenia. In Anoplotaeniinae, the tribes Dasyurotaeniini Spasskii, 1998 (for the rostellate and armed, Dasyurotaenia) and Anoplotaeniini Spasskii, 1998 (for the arostellate and unarmed Anoplotaenia) were established. Thus, a primary character of adult strobilate worms was used to justify the tribes, whereas a combination of morphological characters for adults or larvae or the range of intermediate and definitive hosts were employed to diagnose each of the genera. This proposal embodied much of the taxonomy outlined previously in the Russian literature where a number of genera, proposed for putative inclusive groups within Taenia, were based primarily on characteristics of larvae (e.g., Abuladze, 1964; Korniushin and Sharpilo, 1986; Movsessian, 1989; Bessonov et al., 1994).

A contrasting view was outlined by Verster (1969) who diagnosed 2 major groups within Taenia based on the relative positions of the genital ducts and osmoregulatory canals in strobilate adults. In Taenia, Group I, the genital ducts pass between the osmoregulatory canals; in Taenia, Group II, they are ventral to the canals. Species referred to Group II were postulated to be relatively older or in relatively primitive carnivoran hosts. Verster (1969) relegated to synonymy with Taenia most of the genera of the Taeniinae regarded as valid in the taxonomy proposed by Abuladze (1964); she did not comment on Anoplotaenia, Dasyurotaenia, Cladotaenia, or Paracladotaenia.

This concept for a reduced number of genera within the Taeniidae was supported by Rausch $(1994,1997)$, in part consistent 
with Verster (1969) and Schmidt (1986), who recognized 2 monotypic subfamilies: (1) Taeniinae for Taenia and (2) Echinococcinae for Echinococcus (with Alveococcus as a synonym). Such genera as Hydatigera, Multiceps, Fossor, Monordotaenia, Taeniarhynchus, Tetratirotaenia, and Fimbriotaenia were subsumed as synonyms of Taenia. Additionally, Cladotaenia, Paracladotaenia (earlier referred to Dilepididae by Freeman [1959] and Schmidt [1986]), Anoplotaenia (to Dilepididae by Schmidt [1986]), Dasyurotaenia (to Davaineidae by Schmidt [1986]), and Insinuarotaenia were excluded from the Taeniidae based on the contention that they were morphologically and ontogenetically incompatible (Rausch, 1994, 1997). Additionally, as Rausch $(1994,1997)$ indicated, divergent proposals for taxonomy within the Taeniinae stemmed from varying opinions about the significance of critical morphological characters for both strobilate adults and metacestodes.

Concepts for the structure of Taeniidae and Taeniinae are diverse, although most authorities considered, within the context of their respective studies, that each of the subfamilies, tribes, or genera that were diagnosed represented inclusive monophyletic groups within the family (e.g., Abuladze, 1964; Bessonov et al., 1994; Rausch, 1994; Spasskii, 1998). Monophyly for the Taeniidae has been generally accepted (e.g., Abuladze, 1964; Bessonov et al., 1994; Rausch, 1994, 1997; Spasskii, 1998) and corroborated by phylogenetic studies of the Eucestoda and Cyclophyllidea (Brooks et al., 1991; Hoberg et al., 1999). The Taeniidae is diagnosed as monophyletic within $\mathrm{Cy}$ clophyllidea, and as the putative sister-group of the Metadilepididae + Paruterinidae (see Hoberg et al., 1999), but phylogenetic relationships for species of Taenia remain largely unresolved. There was, however, no formal phylogenetic framework on which the taxonomic structure within Taeniidae was established; either Taeniinae was monotypic (e.g., Verster, 1969; Rausch, 1994, 1997) or relatively diverse, with a maximum of 8-10 genera (e.g., Bessonov et al., 1994; Spasskii, 1998).

These contrasting views of the taxonomic and genealogical diversity of Taenia have never been fully addressed within a phylogenetic context (see Okamoto et al., 1995; De Queiroz and Alkire, 1998). Thus, the degree to which Verster's groups or the array of genera that may be recognized within Taenia represent monophyletic taxa diagnosed by unequivocal characters remains to be evaluated. Attempts to resolve the current discordant taxonomy have relied thus far on distance methods lacking a phylogenetic context (e.g., Murai, et al., 1993; Gubányi, 1995). Indeed, Gubányi (1995) proposed that Taenia could be partitioned into several additional genera based on distance comparisons for morphometric characters of hooks; a phylogenetic basis for this proposal was not presented.

Knowledge of phylogenetic relationships is critical to inferring patterns of character evolution, diagnosis of monophyletic taxa, and elucidation of histories for host association and biogeography (Brooks and McLennan, 1991, 1993). Only 3 studies within Taenia have taken a phylogenetic approach, but these have examined relationships for a limited number of species in the genus (Moore and Brooks, 1987; Okamoto et al., 1995; De Queiroz and Alkire, 1998). Preliminary interpretation of the results of these investigations are consistent in suggesting that Taenia cannot be deconstructed if it is to represent a monophyletic taxon.
In the current study, we present the first comprehensive hypothesis for phylogeny of Taenia based on analysis of structural characters of adults and metacestodes within a comparative morphological context; this represents an extension of studies at the family level within the Cyclophyllidea (Hoberg et al., 1999). We do not examine here the larger issue of the placement of such genera as Anoplotaenia, Dasyurotaenia, or Cladotaenia but focus on phylogeny for species within the Taeniinae sensu stricto. Results of this analysis are applied to: (1) an examination of the taxonomic structure for the subfamily and genus; and (2) a discussion of putative relationships and coevolutionary history for species of Taenia in an array of herbivorous intermediate and carnivorous definitive hosts.

\section{MATERIALS AND METHODS}

Cladistic methods (Hennig, 1966) were applied to the development of an hypothesis for the phylogenetic relationships among species of Taenia. Species considered valid for this analysis were those listed by Verster (1969) and those that were subsequently described, primarily from African carnivores; species considered either as invalid or as inquirendae by Verster (1969) were excluded. In this initial analysis, character data were derived from Abuladze (1964), Verster (1969), original descriptions, and examination of specimens.

Monophyly for Taeniidae is consistent with results of phylogenetic analyses of the Cyclophyllidea (Hoberg et al., 1999), and this analysis forms the basis for outgroup comparisons in the current study. In the analysis of Taenia spp., there were 35 ingroup taxa. Among these species, transformation series were polarized by taxonomic outgroup criteria (Maddison et al., 1984) with reference to basal cyclophyllideans and particularly to Echinococcus that represents the putative sistergroup for Taenia (e.g., Rausch, 1994; Okamoto et al., 1995). Characters 9 and 10 were evaluated with respect to a functional outgroup (Watrous and Wheeler, 1981) represented by the basal species of Taenia. Polymorphism for character 6 was evident in Taenia acinonyxi, Taenia crocutae, Taenia laticollis, Taenia macrocystis, Taenia multiceps and Taenia taeniaeformis; coding in the current study followed the most recent convention and was consistent with estimation of the ancestral condition (Kornet and Turner, 1999). A numerical matrix describing transformation series and characters for species of Taenia was developed from comparative morphological studies of adult and larval cestodes (Table I) and written with MacClade 3.05 (Maddison and Maddison, 1992).

Analysis was conducted with PAUP 3.1.1 (Swofford, 1993). The following parameters were specified: heuristic search (HS), ADD SEQ = simple, single tree held in stepwise addition, MULPARS, and BRANCH SWAPPING by tree bisection-reconnection (TBR); searches with other options yielded substantially longer trees. Bootstrap resampling with 100 replicates (with HS and TBR) was used to examine the relative strength of the phylogenetic hypothesis (see Swofford, 1993).

There were 27 binary and multistate characters in the analysis (Table I); multistate characters were run as unordered. Following development of the character matrix, 5 species, including Taenia ingwei Ortlepp, 1938, T. laticollis Rudolphi, 1819, Taenia pseudolaticollis Verster, 1969, Taenia brachyacantha Baer and Fain, 1951, and Taenia dinniki Jones and Khalil, 1984, all missing a block of data for metacestodes (characters 9-11), were excluded from the analysis. Relationships were examined for the following taxa: T. solium Linnaeus, 1758; T. acinonyx Ortlepp, 1938; Taenia crassiceps (Zeder, 1800); T. crocutae Mettrick and Beverley-Burton, 1961; Taenia endothoracicus (Kirschenblatt, 1948); Taenia gonyamai Ortlepp, 1938; Taenia hyaenae Baer, 1926 Taenia hydatigena Pallas, 1766; T. macrocystis (Diesing, 1850); T. multiceps Leske, 1780; Taenia omissa Lühe, 1910; Taenia ovis (Cobbold, 1869) (including Taenia krabbei Moniez, 1879); Taenia parenchymatosa Pushmenkov, 1945; Taenia pisiformis (Bloch, 1780); Taenia polyacantha Leuckart, 1856; Taenia regis Baer, 1923; Taenia rileyi Loewen, 1929; Taenia saginata Goeze, 1782; Taenia serialis (Gervais, 1847); T. taeniaeformis (Batsch, 1786); Taenia martis Zeder, 1803; Taenia mustelae Gmelin, 1790; Taenia parva Baer, 1926; Taenia selous Mettrick, 1962; Taenia taxidiensis Skinker, 1935; Taenia twitchelli, Schwartz, 1924; Taenia asiatica Eom and Rim, 1993; Taenia madoquae 
TABLE I. Character matrix for phylogenetic analysis of Taenia spp.

\begin{tabular}{|c|c|c|c|c|c|c|c|c|c|c|c|c|c|c|c|c|c|c|c|c|c|c|c|c|c|c|c|}
\hline \multirow[b]{2}{*}{ Taxa } & \multicolumn{27}{|c|}{ Characters } \\
\hline & 1 & 2 & 3 & 4 & 5 & 6 & 7 & 8 & 9 & 10 & 11 & 12 & 13 & 14 & 15 & 16 & 17 & 18 & 19 & 20 & 21 & 22 & 23 & 24 & 25 & 26 & 27 \\
\hline Echinococcus* & 0 & 0 & 0 & 0 & 0 & 0 & 0 & 0 & 0 & 0 & 0 & 0 & 0 & 0 & 0 & 0 & 0 & 0 & 0 & 0 & 0 & 0 & 0 & 0 & 0 & 0 & 0 \\
\hline T. solium & 0 & 2 & 1 & 3 & 1 & 1 & 0 & 0 & 0 & 0 & 3 & 0 & 1 & 1 & 0 & 0 & 1 & 2 & 2 & 1 & 1 & 1 & 1 & 0 & 2 & 2 & 0 \\
\hline T. acinonyxi & 0 & 0 & 1 & 2 & 1 & 0 & 0 & 0 & 0 & 0 & 3 & 0 & 1 & 0 & 0 & 1 & 0 & 1 & 1 & 1 & 1 & 0 & 1 & 0 & 1 & 1 & 1 \\
\hline T. crassiceps & 0 & 0 & 1 & 1 & 0 & 0 & 0 & 1 & 0 & 0 & 2 & 0 & 0 & 1 & 0 & 0 & 0 & 1 & 2 & 1 & 1 & 1 & 1 & 0 & 1 & 0 & 0 \\
\hline T. crocutae & 0 & 0 & 1 & 3 & 2 & 0 & 2 & 1 & 0 & 0 & 3 & 0 & 1 & 0 & 0 & 0 & 1 & 2 & 2 & 1 & 1 & 0 & 1 & 0 & 2 & 2 & 0 \\
\hline T. endothoracicus & 0 & 0 & 1 & 2 & 1 & 0 & 0 & 0 & 0 & 2 & 2 & 0 & 1 & 1 & 0 & 0 & 1 & 0 & 0 & 1 & 1 & 0 & 3 & 1 & 1 & 2 & 1 \\
\hline T. gonyamai & 0 & 0 & 1 & 4 & 1 & 1 & 2 & 1 & 0 & 0 & 3 & 0 & 1 & 0 & 0 & 0 & 0 & 2 & 0 & 1 & 1 & 0 & 1 & 0 & 1 & 2 & 1 \\
\hline T. hyaenae & 0 & 0 & 1 & 2 & 1 & 1 & 2 & 1 & 0 & 0 & 3 & 0 & 0 & 1 & 0 & 0 & 1 & 2 & 0 & 1 & 1 & 0 & 1 & 0 & 2 & 2 & 0 \\
\hline T. hydatigena & 0 & 0 & 1 & 4 & 1 & 1 & 0 & 1 & 0 & 0 & 1 & 0 & 1 & 0 & 1 & 0 & 1 & 1 & 2 & 0 & 1 & 0 & 1 & 0 & 2 & 2 & 1 \\
\hline T. ingwei & 0 & 0 & 1 & 4 & 1 & 1 & 2 & 1 & $? \dagger$ & $?$ & $?$ & 0 & 0 & 1 & 0 & 0 & 0 & 1 & 0 & 0 & 1 & 0 & 1 & 0 & 1 & 1 & 1 \\
\hline T. laticollis & 0 & 0 & 1 & 2 & 0 & 0 & 0 & 1 & $?$ & $?$ & $?$ & 0 & 1 & 1 & 0 & 0 & 1 & 1 & 0 & 1 & 1 & 0 & 3 & 1 & 1 & 1 & 0 \\
\hline T. macrocystis & 0 & 0 & 1 & 3 & 0 & 0 & 0 & 0 & 0 & 0 & 1 & 1 & 1 & 1 & 1 & 0 & 1 & 1 & 0 & 1 & 1 & 0 & 3 & 1 & 1 & 0 & 1 \\
\hline T. multiceps & 0 & 0 & 1 & 2 & 1 & 0 & 1 & 0 & 0 & 1 & 3 & 1 & 1 & 0 & 1 & 1 & 1 & 2 & 1 & 1 & 1 & 0 & 3 & 0 & 2 & 1 & 0 \\
\hline T. omissa & 0 & 0 & 1 & 2 & 1 & 1 & 2 & 1 & 0 & 0 & 0 & 1 & 1 & 1 & 1 & 0 & 1 & 1 & 2 & 0 & 1 & 0 & 2 & 0 & 1 & 2 & 1 \\
\hline T. ovis & 0 & 0 & 1 & 4 & 2 & 1 & 2 & 0 & 0 & 0 & 3 & 0 & 1 & 0 & 1 & 1 & 0 & 1 & 1 & 0 & 0 & 1 & 1 & 0 & 2 & 2 & 1 \\
\hline T. parenchymatosa & 0 & 0 & 1 & 3 & 1 & 1 & 0 & 1 & 0 & 0 & 0 & 0 & 1 & 0 & 0 & 0 & 1 & 1 & 2 & 1 & 1 & 1 & 1 & 0 & 2 & 2 & 1 \\
\hline T. pisiformis & 0 & 0 & 1 & 4 & 0 & 1 & 0 & 0 & 0 & 0 & 1 & 0 & 0 & 0 & 0 & 1 & 1 & 2 & 1 & 1 & 0 & 0 & 2 & 0 & 2 & 1 & 0 \\
\hline T. polyachantha & 0 & 0 & 1 & 2 & 1 & 1 & 0 & 1 & 0 & 3 & 2 & 0 & 1 & 0 & 1 & 0 & 0 & 1 & 2 & 1 & 1 & 1 & 1 & 1 & 1 & 1 & 1 \\
\hline T. pseudolaticollis & 0 & 0 & 1 & 2 & 2 & 1 & 0 & 1 & $?$ & $?$ & $?$ & 0 & 1 & 1 & 0 & 1 & 1 & 1 & 1 & 0 & 1 & 1 & 5 & 0 & 1 & $?$ & 1 \\
\hline T. regis & 0 & 0 & 1 & 3 & 1 & 1 & 2 & 1 & 0 & 0 & 1 & 0 & 1 & 1 & 1 & 1 & 0 & 1 & 1 & 0 & 1 & 0 & 2 & 0 & 1 & 2 & 1 \\
\hline T. rileyi & 0 & 0 & 1 & 3 & 2 & 1 & 1 & 1 & 1 & 0 & 0 & 0 & 1 & 1 & 0 & 0 & 0 & 1 & 2 & 0 & 0 & 1 & 1 & 0 & 1 & 2 & 1 \\
\hline T. saginata & 1 & 3 & 1 & 5 & 2 & 1 & 2 & 1 & 0 & 0 & 3 & 0 & 1 & 0 & 0 & 0 & 1 & 2 & 1 & 0 & 1 & 0 & 4 & 2 & 2 & 2 & 1 \\
\hline$T$. serialis & 0 & 0 & 1 & 3 & 1 & 1 & 2 & 1 & 0 & 1 & 3 & 0 & 1 & 1 & 0 & 1 & 1 & 1 & 0 & 1 & 0 & 0 & 2 & 0 & 1 & 1 & 0 \\
\hline T. taeniaeformis & 0 & 0 & 0 & 3 & 0 & 0 & 2 & 1 & 1 & 0 & 0 & 0 & 0 & 1 & 0 & 0 & 0 & 0 & 2 & 1 & 1 & 2 & 3 & 0 & 1 & 2 & 1 \\
\hline T. brachyacantha & 0 & 0 & 0 & 1 & 0 & 1 & 0 & 0 & $?$ & $?$ & $?$ & 0 & 1 & 1 & 0 & 1 & 1 & 0 & 2 & 1 & 1 & 0 & 0 & 1 & 0 & 0 & $?$ \\
\hline T. martis & 0 & 0 & 0 & 1 & 1 & 1 & 0 & 1 & 0 & 3 & 2 & 0 & 0 & 1 & 0 & 1 & 1 & 1 & 2 & 0 & 0 & 1 & 1 & 0 & 0 & 0 & 1 \\
\hline T. mustelae & 0 & 0 & 0 & 1 & 0 & 0 & 0 & 0 & 0 & 0 & 0 & 0 & 1 & 1 & 0 & 1 & 0 & 1 & 0 & 0 & 1 & 0 & 0 & 0 & 1 & 0 & 1 \\
\hline T. parva & 0 & 0 & 0 & 3 & 0 & 1 & 0 & 0 & 1 & 0 & 1 & 0 & 0 & 1 & 0 & 0 & 1 & 1 & 2 & 1 & 1 & 2 & 3 & 0 & 0 & 1 & 1 \\
\hline T. selousi & 0 & 0 & 0 & 2 & 0 & 1 & 0 & 0 & 0 & 2 & 1 & 0 & 1 & 1 & 0 & 0 & 0 & 1 & 2 & 1 & 0 & 2 & 2 & 1 & 1 & 0 & 0 \\
\hline$T$. taxidiensis & 0 & 1 & 0 & 1 & 1 & 1 & 0 & 1 & 0 & 0 & 3 & 0 & 0 & 1 & 0 & 0 & 0 & 1 & 2 & 0 & 0 & 1 & 1 & 0 & 1 & 1 & 1 \\
\hline T. twitchelli & 0 & 0 & 0 & 1 & 1 & 1 & 0 & 1 & 0 & 2 & 2 & 0 & 0 & 1 & 0 & 1 & 0 & 0 & 2 & 1 & 0 & 1 & 1 & 0 & 1 & 1 & 1 \\
\hline T. asiatica & 1 & 3 & 1 & 5 & 1 & 1 & 2 & 0 & 0 & 0 & 1 & 0 & 1 & 1 & 0 & 0 & 1 & 1 & 1 & 1 & 1 & 0 & 4 & 2 & 2 & 2 & 1 \\
\hline T. dinniki & 0 & 0 & 1 & 3 & 1 & 1 & 2 & 1 & $?$ & $?$ & $?$ & 0 & 1 & 1 & 1 & 1 & 1 & 2 & 2 & 1 & 1 & 0 & 2 & 0 & 1 & 1 & 1 \\
\hline T. madoquae & 0 & 0 & 0 & 3 & 1 & 1 & 2 & 1 & 0 & 0 & 3 & 0 & 1 & 0 & 0 & 0 & 1 & 2 & 2 & 1 & 1 & 2 & 1 & 0 & 1 & 2 & 1 \\
\hline T. olngojinei & 0 & 0 & 0 & 3 & 1 & 1 & 0 & 0 & 0 & 0 & 3 & 1 & 1 & 0 & 1 & 0 & 1 & 1 & 2 & 1 & 1 & 1 & 3 & 0 & 1 & 1 & 0 \\
\hline T. simbae & 0 & 0 & 1 & 5 & 1 & 1 & 2 & 0 & 0 & 0 & 1 & 0 & 0 & 1 & 0 & 0 & 1 & 1 & 1 & 0 & 1 & 0 & 2 & 0 & $?$ & $?$ & $?$ \\
\hline
\end{tabular}

* Outgroup and putative sister group for Taenia.

† Missing data designated as "?".

(Pellegrini, 1950); Taenia olngojinei Dinnik and Sachs, 1969; and Taenia simbae Dinnik and Sachs, 1972.

Results of the analyses are depicted as the most parsimonious phylogenetic tree(s) (MPTs) with associated statistics including the consistency index (CI), rescaled consistency index (RC), retention index (RI), and homoplasy index (HI) as defined in Swofford and Begle (1993). Consensus trees ( $50 \%$ majority rule) were used to examine relationships when more than a single MPT resulted from the analysis.

Host-parasite relationships and putative historical associations for parasites and hosts were examined by mapping extant host taxa (family level) onto the parasite tree. This was accomplished by using matrices for intermediate or definitive hosts (not shown) and optimizing these as characters on the parasite phylogeny with MacClade 3.05 (Maddison and Maddison, 1992). Data for life history and host distributions were derived primarily from Abuladze (1964), Sachs (1969), Verster (1969), Dinnik and Sachs $(1969,1972)$, Rausch $(1977,1981)$, and Jones et al. (1988).

\section{RESULTS}

\section{Character descriptions for Taenia spp.}

1. Hooks. $0=$ present; $1=$ absent.

2. Hooks. Number of rostellar hooks. Three states. $0=2$ rows; $1=1$ row; $2=3$ rows; $3=$ absent.
3. Position of genital ducts. In some species of Taenia and all Echinococcus the genital ducts pass outside the excretory canals. $0=$ beyond the canals; $1=$ between the canals.

4. Mean number of testes. Although the number of testes is difficult to determine, their mean value may reflect actual differences as discrete subsets. Most cyclophyllideans basal to the Taeniidae and the putative sister-group represented by the $\mathrm{Me}$ tadilepididae + Paruterinidae have relatively few testes (Hoberg et al., 1999). $0=\leq 60 ; 1=100-200 ; 2=250 \approx 350 ; 3=\approx 400$ to $\leq 600 ; 4=>600-700 ; 5=>800$.

5 . Length of cirrus sac. The actual length of the cirrus sac is highly variable and often dependent on the age of the proglottid. Relative length (in relation to the position of the excretory canals), however, can be well defined, and an elongate cirrus sac is considered plesiomorphic. $0=$ cirrus sac long (extending across canals); 1 = intermediate (extending to poral canals); 2 = short (not extending to canals).

6. Size of ovarian lobes. Lobation of the ovary is a synapomorphic condition in the Taeniidae. All species have 2 lobes 
except $T$. solium that has 3 . The relative size of the lobes appears to be species specific (Verster, 1969). Polymorphism is evident in $T$. acinonyxi, $T$. crocutae, $T$. laticollis, $T$. macrocystis, T. multiceps, and T. taeniaeformis, and these taxa are coded as plesiomorphic, consistent with the ancestral condition. $0=$ lobes equal to subequal; $1=$ antiporal lobe larger than poral lobe.

7. Vaginal sphincter. In many species a well developed vaginal sphincter is apparent, whereas in 2 species there is partial development of the sphincter. Presence of a sphincter is derived in Taenia. 0 = absent; $1=$ incompletely developed; 2 = completely developed.

8. Vaginal dilatation. In some species the vagina has a characteristic dilatation proximal to the genital pore. This condition is not observed in species of Echinococcus. $0=$ without dilatation; 1 = with dilatation.

9. Larval structure, mature metacestode strobilocercus. This character is considered for those species where the life cycle has been elucidated. The cysticercus and inclusive larval forms, represent a synapomorphy for Taenia. Coding for characters 9 and 10 is based on functional outgroup criteria, where the cysticercus is defined as plesiomorphic relative to the basal species of Taenia in preliminary analyses. The strobilocercus is considered to be derived from the cysticercus and is postulated as independent of other larval forms defined for species of Taenia. The strobilocercus, a strobilate metacestode with well developed scolex and prominent segmentation, is present in T. taeniaeformis and $T$. parva. The hemistrobilocysticercus, a larval form described for $T$. rileyi (see Rausch, 1981) is included here and is considered as intermediate to the cysticercus and strobilocercus. The coenurostrobilocercus larval form in $T$. parva is considered to be homologous with the strobilocercus (Murai et al., 1989). 0 = cysticercus; $1=$ strobilocercus.

10. Larval structure, mature metacestode. The coenurus, polycephalic, and fimbriated larval forms are derived with respect to the cysticercus, but their ontogenetic relationships and homology are uncertain. Although both cysticercus and polycephalic larvae are known for T. mustelae (see Freeman, 1956), the former is postulated to be plesiomorphic (contrary to Crusz, 1948). Abuladze (1964) established Tetratirotaenia and defined the armatetrathyridium larva for $T$. polyacantha. Korniushin and Sharpilo (1986) recognized the fimbriated form as characteristic of T. martis, T. mustelae, T. twitchelli, and T. brachyacantha and established Fimbriotaenia. In contrast, Rausch (1977) and Rausch and Fay (1988a, 1988b) considered the larval form defined for $T$. polyacantha to be similar to that of $T$. martis and that these differed substantially from the polycephalic metacestodes of $T$. twitchelli. $0=$ cysticercus; $1=$ coenurus (multiple scolices that develop by invagination into a central bladder-T. serialis, T. multiceps); $2=$ polycephalic (protoscolices on elongate stalks that arise by exogenous budding from a central bladder that later regresses-T. selousi, $T$. endothoracicus, $T$. twitchelli); 3 = fimbriated (invaginated scolex, elongate, unsegmented larvae with characteristic folds-T. martis, T. brachyacantha, $T$. polyacantha).

11. Localization of the metacestode in the intermediate host. The site of larval development is generally species specific and without substantial variation. Several patterns of localization can be defined as follows and are related to where the hexacanth localizes with respect to the circulatory system of the inter- mediate host: (a) hepatic, (b) peritoneal, (c) thoracic, and (d) systemic, usually intramuscular. $0=$ hepatic; $1=$ peritoneal; 2 $=$ thoracic 3 = systemic.

12. Testes, distribution and degree of confluence in anterior of proglottid. $0=$ confluent; $1=$ not confluent.

13. Testes, distribution and degree of confluence posterior to vitellaria. $0=$ confluent; $1=$ not confluent.

14. Testes, distribution and gap or discontinuity in field at level of the genital ducts. $0=$ gap present; 1 = gap absent.

15. Testes distribution, fields disposed evenly or laterally. 0 = even; 1 = laterally.

16. Genital papilla. Two states. $0=$ absent; $1=$ present

17. Uterine branches. $0=$ lacking terminal bifurcation; $1=$ with terminal bifurcation.

18. Genital pore, position on lateral margin of mature proglottid. $0=$ anterior; $1=$ median; $2=$ posterior.

19. Vas deferens, route followed from cirrus sac relative to location of genital pore. $0=$ anterior; $1=$ median; $2=$ posterior.

20. Testes, numbers of layers. $0=1 ; 1=>2$.

21. Vitellaria, shape of lobes. $0=$ rounded; $1=$ flattened.

22. Cirrus sac, shape. $0=$ club or pear; $1=$ ovoid; $2=$ flask.

23. Large rostellar hooks, mean length. $0=<50 \mu \mathrm{m} ; 1=$ $100-200 ; 2=250-300 ; 3=>300$.

24. Rostellar hooks, mean number. The number of rostellar hooks is usually distinctive, and 6 species have $>54$ hooks, whereas the remainder have $22-44.0=<44$ hooks; $1=>54$ hooks.

25. Length of strobila (when gravid). $0=$ small, $<10 \mathrm{~cm} ; 1$ $=$ medium, $>10 \mathrm{~cm}$ to $\leq 75 \mathrm{~cm} ; 2=$ large, $>1 \mathrm{~m}$.

26. Width, maximum in gravid segments. $0=1-2 \mathrm{~mm} ; 1=$ $3-5 \mathrm{~mm} ; 2=>6 \mathrm{~mm}$.

27. Mature proglottids, shape. $0=$ longer than wide; $1=$ wider than long.

\section{Phylogeny for Taenia spp.}

Analysis of a numerical data matrix describing characters for species of Taenia resulted in 4 MPTs (174 steps; CI $=0.28$; $\mathrm{HI}=0.72 ; \mathrm{RI}=0.48$ ). Consensus trees (strict and $50 \%$ majority rule are congruent) were used to summarize multiple, equal length trees (Fig. 1). Bootstrap resampling did not reveal strong support for any nodes. The 4 MPTs were largely congruent, differing only in relationships postulated within $3 \mathrm{de}-$ rived subclades: (1) relationships for $T$. twitchelli or $T$. taxidiensis as the sister species for $T$. martis within a $T$. polyacantha subclade; (2) the relationships among $T$. ovis, $T$. hydatigena, $T$. omissa, and $T$. regis as basal taxa within a $T$. hydatigena subclade that also contains $T$. simbae and $T$. saginata $+T$. asiatica; and (3) a basal polytomy in the T. madoquae subclade that also contains $T$. solium.

Monophyly for Taenia is diagnosed by the metacestode that is either a cysticercus or a form derived from a bladder-like larva. The genus is further diagnosed by a series of equivocal attributes that include characters influenced by homoplasy within the ingroup (apomorphic character states acquired basally, with either independent reversal or parallelism/convergence in crown taxa): (1) a high number of testes (character 4); (2) testes that are not confluent posterior to the vitelline gland (character 


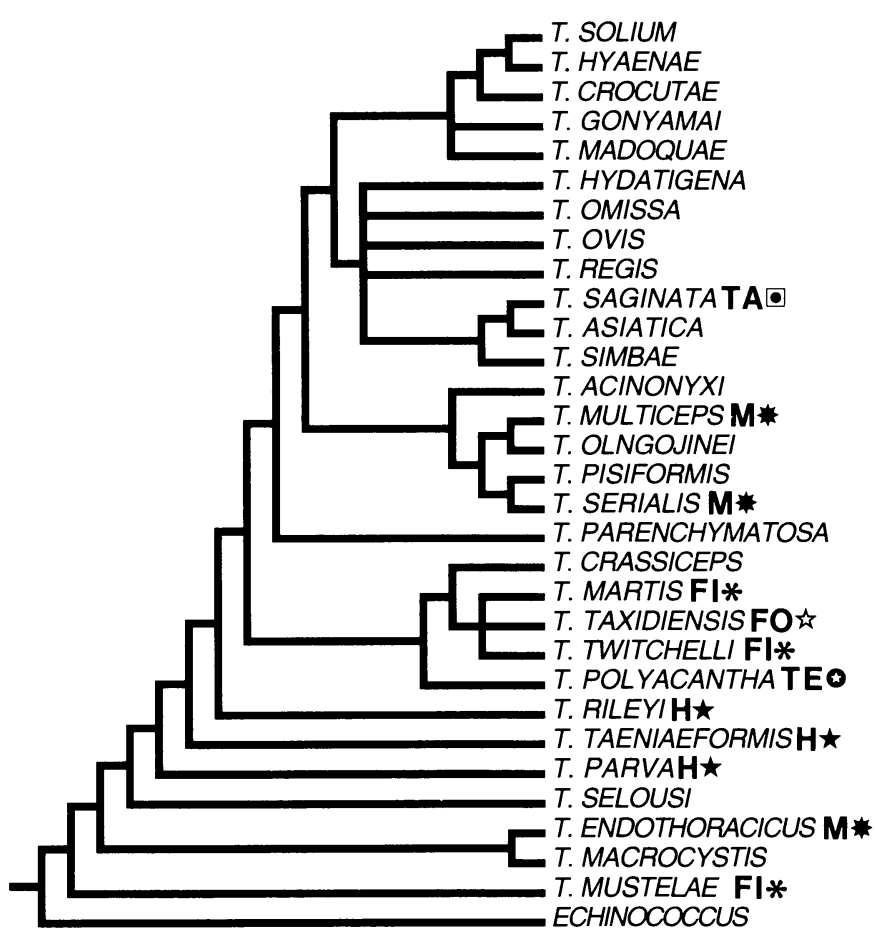

FIGURE 1. Phylogenetic hypothesis for species of Taenia based on analysis of comparative morphological data. Analysis resulted in 4 equal length trees ( 174 steps; $\mathrm{CI}=0.28 ; \mathrm{HI}=0.72$; $\mathrm{RI}=0.48)$; shown is the $50 \%$ majority rule consensus tree (all nodes at $100 \%$ ) derived from the 4 most parsimonious trees. Coding associated with terminal taxa indicates previous generic-level placement for respective species: $\mathrm{FI}=$ Fimbriotaenia $; \mathrm{FO}=$ Fossor/Monordotaenia $; \mathrm{H}=$ Hydatigera $;$ $\mathrm{M}=$ Multiceps; $\mathrm{TA}=$ Taeniarhynchus; $\mathrm{TE}=$ Tetratirotaenia ; repeated symbols indicate species referred to the same genus. Based on this hypothesis, these genera do not constitute inclusive monophyletic groups and should be subsumed as synonyms of the genus Taenia, consistent with Rausch (1994, 1997).

13); (3) a gap in the field of testes at the level of the genital ducts (character 14); (4) a median to posterior marginal genital pore (character 18); (5) flattened lobes of the vitelline gland (character 21); (6) generally medium to large strobila (character $25)$; and (7) mature proglottids that are often wider than long (character 27). These and other characters were mapped onto 1 of the MPTs in order to examine character evolution and support for the phylogenetic hypothesis for Taenia spp. (Fig. 2). Consistency indices for individual characters are summarized in Table II. Homoplasy was associated with 25 of 27 characters. Among these, 22 characters exhibited CIs substantially $<0.50$, further indicative of plasticity for structural, ontogenetic, and ecological attributes of Taenia spp.

Considering the overall topology for this hypothesis, T. mustelae is basal in the genus. There are 5 subclades within the largely resolved phylogeny, including: (1) $T$. macrocystis $+T$. endothoracicus; (2) $T$. polyacantha with $T$. crassiceps $+T$. martis, $T$. twitchelli, and $T$. taxidiensis in a polytomy; (3) $T$. acinonyxi with $T$. multiceps $+T$. olngojinei and $T$. serialis + $T$. pisiformis; (4) $T$. hydatigena in a polytomy with $T$. omissa, $T$. ovis, $T$. regis, and $T$. simbae $+T$. asiatica $+T$. saginata; and (5) $T$. madoquae in a polytomy with $T$. gonyamai and $T$. crocutae $+T$. hyaenae $+T$. solium. Notably, $T$. solium does not share a close common ancestor with $T$. saginata. Tree struc- ture and partitioning of these subclades provides no support for recognition of a diversity of tribes or genera within Taeniinae (Fig. 1). The tribes, Fimbriotaeniini and Taeniini have no phylogenetic basis. Hydatigera, Fimbriotaenia, Fossor, Monordotaenia, Multiceps, Taeniarhynchus, and Tetratirotaenia must be subsumed within Taenia, as they do not represent discrete monophyletic taxa (Fig. 1).

\section{Parasite-host relationships}

Definitive and intermediate hosts for Taenia spp. were mapped onto the parasite phylogeny (Figs. 3, 4). Definitive hosts are represented by Viverridae, Mustelidae, Hyaenidae, Canidae, Felidae, and Hominidae; minimal consistency in host distribution is apparent $(\mathrm{CI}=0.46, \mathrm{RI}=0.53 ; \mathrm{RC}=0.25)$ (Fig. 3). Felids may be ancestral definitive hosts for Taenia, and extensive colonization among a diverse assemblage of carnivores, particularly canids and felids, is postulated. Basal species are primarily found in felids and relatively derived species in canids as a subsequent source for cestodes in mustelids, some felids, and hyaenids. Limited cospeciation is postulated within the $T$. polyacantha subclade, for $T$. twitchelli, $T$. taxidiensis, and $T$. martis in mustelids and for $T$. saginata $+T$. asiatica in humans.

Intermediate hosts are represented by Rodentia, Artiodactyla (principally in Bovidae, Cervidae, Suidae), and rarely by Lagomorpha, Hyracoidea (Procaviidae), Canidae, and Primates (including Hominidae); a high consistency in host relationships is observed $(\mathrm{CI}=0.89 ; \mathrm{RI}=0.85 ; \mathrm{RC}=0.75$ ) (Fig. 4). Basal species and subclades are all associated with rodent intermediate hosts, except for T. macrocystis; and minimally, a single colonization of artiodactyls is postulated. Lagomorphs rarely occur as intermediate hosts ( $T$. macrocystis, $T$. serialis, $T$. pisiformis), and the occurrence of Taenia in these mammals is compatible with 2 independent colonization events. Suid intermediate hosts are rare and associated typically with species that occur as adults in humans; e.g., $T$. asiatica and $T$. solium, and with putative host switches for $T$. regis and $T$. acinonyxi. Records for $T$. multiceps and $T$. hydatigena in domestic suids are likely incidental and were not included.

\section{DISCUSSION}

\section{Contrasting phylogenetic hypotheses}

The current analysis represents the first comprehensive and testable hypothesis for relationships for species in the genus Taenia. Conclusions and interpretations herein contrast with analyses presented by Moore and Brooks (1987), Okamoto et al. (1995), and De Queiroz and Alkire (1998). This may reflect uneven and incomplete sampling of taxa in these previous studies but also is indicative of some level of instability in the current tree(s), consistent with extensive levels of homoplasy for most structural attributes. Remarkable plasticity in morphology and ontogeny as documented in prior phylogenetic studies by Moore and Brooks (1987) is apparent (Table II; Fig. 2).

All available analyses place $T$. mustelae as the basal species in the genus (Moore and Brooks, 1987; Okamoto et al., 1995; De Queiroz and Alkire, 1998). Moore and Brooks (1987), evaluated relationships among 13 species of Taenia and in part 


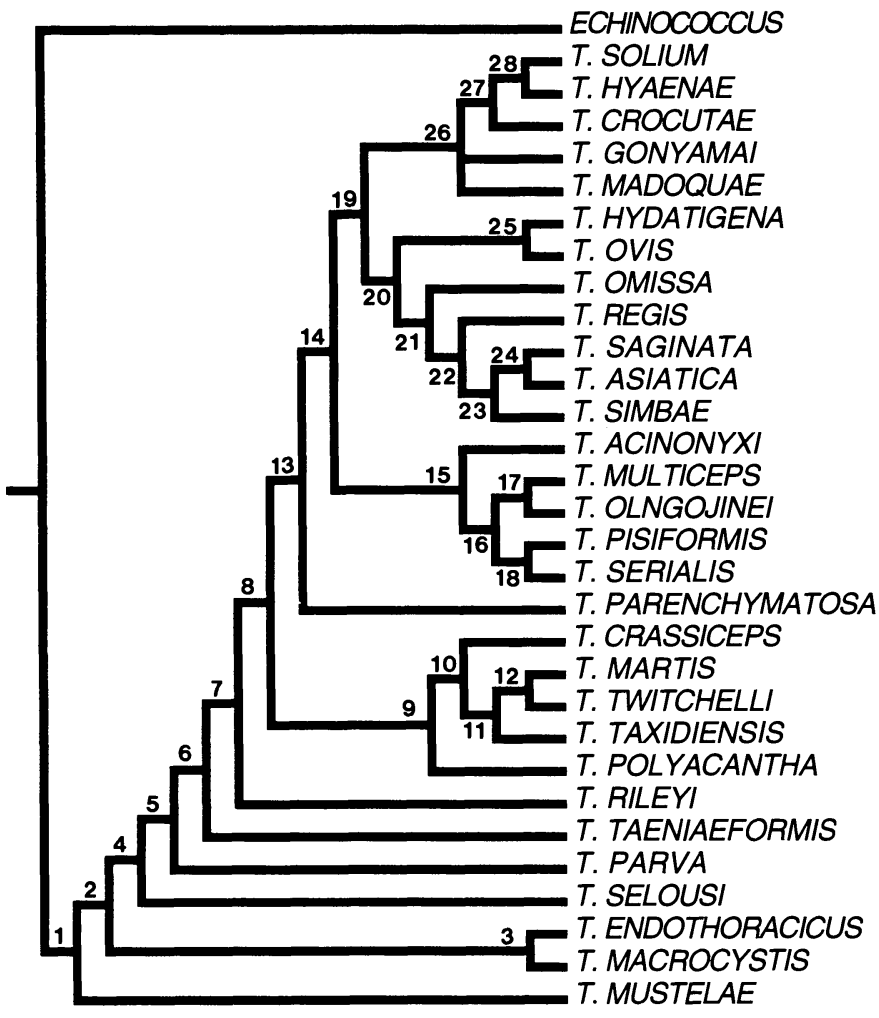

FIGURE 2. Phylogenetic hypothesis for species of Taenia based on analysis of comparative morphological data. Shown is 1 of 4 equallength trees, largely congruent with the consensus tree (Fig. 1). Characters are mapped onto the tree and show the distribution of morphological attributes among terminal taxa and support for each node (numbered sequentially from the base of the tree); $\mathrm{A}=$ apomorphy, $\mathrm{H}=$ homoplasy as convergence or parallelism, $\mathrm{R}=$ reversal. Terminal taxa: T. mustelae (H: 16); T. macrocystis $(\mathrm{H}: 4,12,15) ;$ T. endothoracicus (A: 26; H: 5, 10,11; R: 18); T. selousi $(\mathrm{H}: 10,13,27 ; \mathrm{R}: 21) ; T$. parva (H: 17; R: 25); T. taeniaeformis $(\mathrm{H}: 3 ; \mathrm{R}: 6,18) ;$ T. rileyi $(\mathrm{H}: 5,7 ; \mathrm{R}$ : $6,18) ; T$. polyacantha $(\mathrm{H}: 4,10,15,24) ; T$. taxidiensis $(\mathrm{A}: 2 ; \mathrm{H}: 11)$ T. twitchelli (H: 20; R: 18); T. martis (H: 10, 17, 16; R: 25); T. crassiceps $(\mathrm{H}: 26,27 ; \mathrm{R}: 5,6) ; T$. parenchymatosa $(\mathrm{H}: 25) ;$. serialis $(\mathrm{H}$ : 7, 8, 10, 14, 19); T. pisiformis $(\mathrm{H}: 4,18,25 ; \mathrm{R}: 5,11,13)$; T. olngojinei (H: 19; R: 3, 16, 22); T. multiceps (H: 4, 7, 10; 18; 25; R: 6); T. acinonyxi (H: 4; R: 6, 17); T. simbae (R: 1); T. asiatica (H: 20); T. saginata $(\mathrm{H}: 5,8,11,18 ; \mathrm{R}: 14) ; T$. regis $(\mathrm{H}: 16 ; \mathrm{R}: 17) ;$. omissa $(\mathrm{H}$ : 12; R: 4, 11); T. ovis $(\mathrm{H}: 5,16,19 ; \mathrm{R}: 8,11,17,21,22) ; T$. hydatigena (R: 7); T. madoquae (H: 22; R: 3); T. gonyamai (H: 4; R: 17, 19); T crocutae (H: 4; R: 6); T. hyaenae (H: 4, 13, 19); T. solium (A: 2; R: $7,8,22$ ). Internodes beginning basally are designated 1-28: 1: A: 4, $13,14,18,21,25,27 ; 2:$ A: $11,20,23,24 ; \mathrm{H}: 4 ; 3$ : H: 3, 17; 4: A: 6, 19; H: 22; 5: A: 4, 9, 26; R: 13, 24; 6: A: 26; H: 8; R: 11; 7: A: 22,23 ; H: $3,5,13 ; 8:$ R: 9,$14 ; 9:$ A: $11 ; \mathrm{H}: 26$; R: 4; 10: H: 14 ; R 13; 11: R: $3,20,21$; 12: H: 10, 16; 13: H: 17; 14: A: 11,$22 ; 15: H:$ 16, 19, 26; R: 8; 16: H: 23, 27; 17: A: 23 ; H: 12, 15; 18: R: 21; 19: H: 7; 20: A: $11 ; \mathrm{H}: 15$; R: 20; 21: H: 14, 23; 22: H: 19; 23: A: 4; R: 8, 15; 24: A: $1,2,23,24 ;$ 25: H: 4, 25; 26: H: 18; 27: H: 25, 27; 28: $\mathrm{H}: 14$.

consistent with the current study, placed $T$. selousi, $T$. taxidiensis, T. martis, $T$. twitchelli, and $T$. crassiceps as relatively basal and closely related; $T$. pisiformis and $T$. serialis were adjacent; and $T$. ovis, $T$. hydatigena, and $T$. omissa were placed near the crown of the tree. In contrast, Moore and Brooks (1987) placed $T$. taeniaeformis and $T$. rileyi in a polytomy with such derived taxa as $T$. omissa and $T$. hydatigena.

De Queiroz and Alkire (1998) evaluated molecular sequence
TABLE II. Consistency indices for individual characters used in analysis of Taenia spp.

\begin{tabular}{clc}
\hline Character no. & \multicolumn{1}{c}{ Character } & CI \\
\hline 1 & Hooks (presence) & 1.000 \\
2 & Hooks (number) & 1.000 \\
3 & Genital ducts & 0.200 \\
4 & Testes (number) & 0.357 \\
5 & Cirrus sac (length) & 0.250 \\
6 & Ovarian lobes & 0.167 \\
7 & Vaginal sphincter & 0.286 \\
8 & Vaginal dilatation & 0.143 \\
9 & Larva & 0.500 \\
10 & Larva & 0.429 \\
11 & Localization & 0.273 \\
12 & Testes (distribution) & 0.333 \\
13 & Testes (distribution) & 0.143 \\
14 & Testes (distribution) & 0.143 \\
15 & Testes (distribution) & 0.200 \\
16 & Genital papilla & 0.143 \\
17 & Uterine branches & 0.125 \\
18 & Genital pore & 0.250 \\
19 & Vas deferens & 0.250 \\
20 & Testes (layers) & 0.200 \\
21 & Vitellaria (shape) & 0.167 \\
22 & Cirrus sac (shape) & 0.286 \\
23 & Rostellar hooks (length) & 0.571 \\
24 & Rostellar hooks (number) & 0.500 \\
25 & Strobila (length) & 0.222 \\
26 & Segment (gravid width) & 0.286 \\
27 & Proglottid (shape) & 0.200 \\
\hline & &
\end{tabular}

data for 12 species of Taenia, including data from Okamoto et al. (1995). Consistent with the current analysis, T. crassiceps was relatively basal; $T$. saginata and $T$. asiatica are putative sister species; and $T$. solium does not share a very recent common ancestor with $T$. saginata. Congruence with the current hypothesis was otherwise limited.

De Queiroz and Alkire (1998) suggested that pending the evaluation of additional characters, both molecular and morphological, competing hypotheses for phylogenetic relationships among species of Taenia must be viewed with caution. The current study included 27 characters, in contrast to 19 applied in the analysis by Moore and Brooks (1987). Morphologically the group is relatively homogenous, and there are likely to be few additional attributes available from comparative morphology. Perhaps conclusions being drawn from multivariate analyses of morphometric data for hooks maybe applied to phylogenetic studies for Taenia (e.g., Murai et al., 1993; Gubányi, 1995). At present, however, representation and evaluation of multivariate data in a form suitable for phylogenetic systematics is problematic (Pimentel and Riggins, 1987).

\section{Phylogeny and taxonomic structure}

Diagnosis of a multitude of tribes or genera in the family Taeniidae and subfamily Taeniinae is not supported (e.g., consistent with Verster [1969] and Rausch [1994, 1997]). A reticulate versus compact or lobate vitellarium does not diagnose groups at the tribe level within Taeniinae; the tribes, Taeniini and Fimbriotaeniini recognized by Spasskii (1998) do not con- 


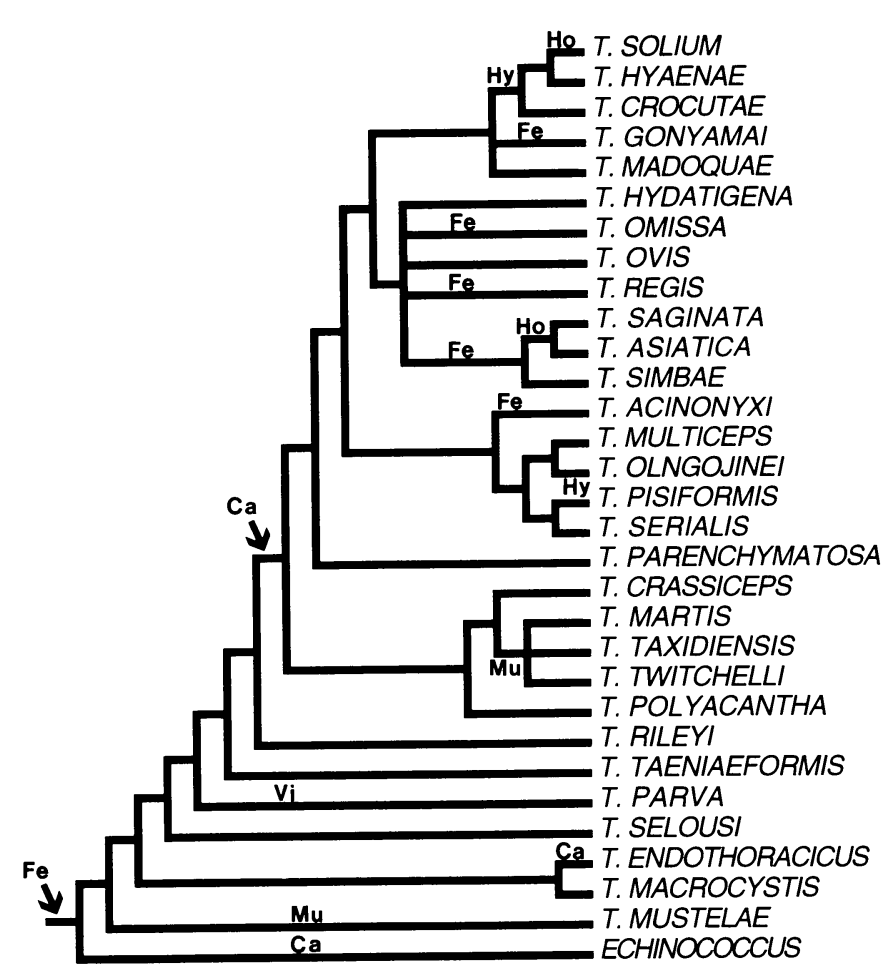

FIGURE 3. Phylogenetic hypothesis for species of Taenia showing distribution of definitive hosts mapped and optimized on the parasite cladogram $(\mathrm{CI}=0.46 ; \mathrm{RI}=0.53 ; \mathrm{RC}=0.25)$. Definitive hosts are represented by Viverridae $=\mathrm{Vi}$, Mustelidae $=\mathrm{Mu}$, Hyaenidae $=\mathrm{Hy}$, Canidae $=\mathrm{Ca}$, Felidae $=\mathrm{Fe}$, and Hominidae $=$ Ho. Patterns are consistent with extensive levels of host-switching in the diversification of Taenia spp.

stitute inclusive monophyletic groups. Additionally, observations by one of us (A. Jones, unpubl. obs.) suggest that the reticulate vitellarium may be an artifact of fixation.

Interpretation of the current phylogenetic hypothesis is consistent with a restricted number of valid genera within the Taeniinae (Fig. 1). For example, even though $T$. saginata and $T$. asiatica are placed as sister species there remains no phylogenetic support for recognition of Taeniarhynchus. Although this genus has been defined primarily by the absence of a rostellum, its recognition would make Taenia paraphyletic. It is also apparent that the structure of larval parasites is inadequate for the delineation of genera. Thus, Hydatigera that was based on the presence of a strobilocercus larva (Abuladze, 1964; Movsessian, 1989; Bessonov et al., 1994) and included T. taeniaeformis, T. parva, and T. rileyi, and several other species, some of which are now either synonyms or species inquerendae (see Verster, 1969) cannot be justified. Fimbriotaenia, established for T. martis, T. twitchelli, T. mustelae, and T. brachyacantha is invalidated because the fimbriocercus larval form does not diagnose a group, and $T$. mustelae is not closely related to either T. martis or T. twitchelli. Additionally, the coenurus larva does not diagnose an inclusive group containing $T$. serialis and $T$. multiceps.

The following genera (inclusive with those listed by Rausch [1994]) become unequivocal synonyms of Taenia, consistent with monophyly for the genus (Fig. 1): (1) based on larvae, Multiceps, Tetratirotaenia, Hydatigera, and Fimbriotaenia; and

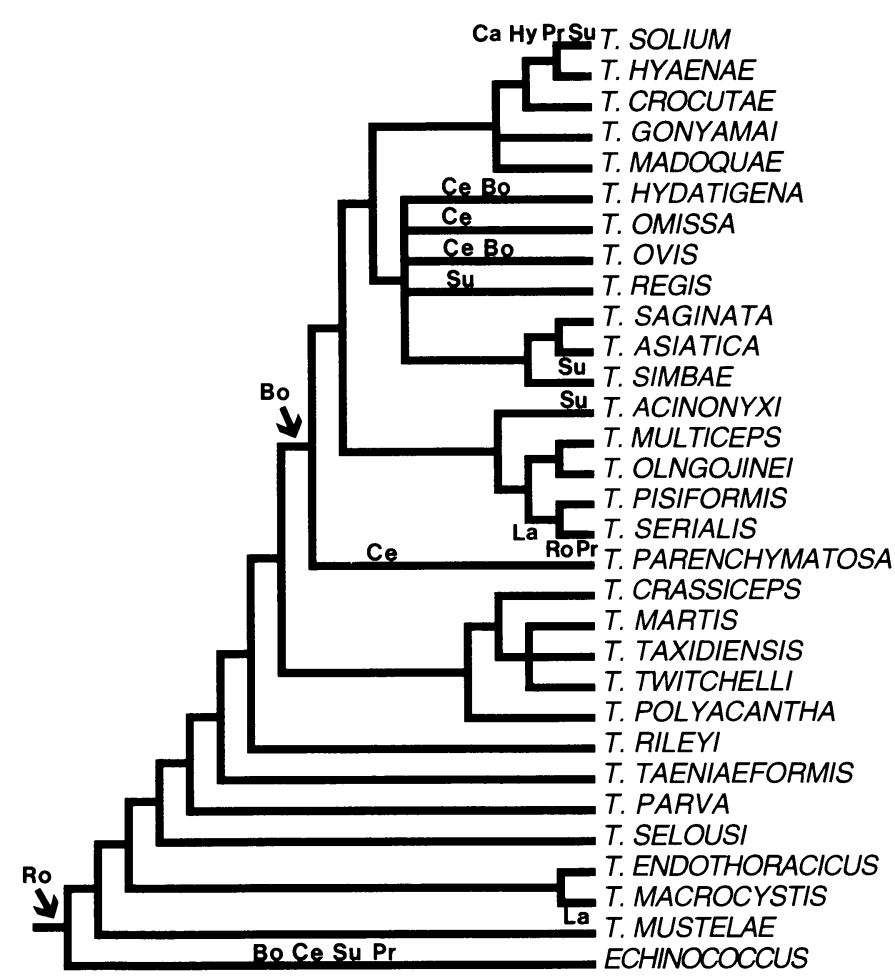

Figure 4. Phylogenetic hypothesis for species of Taenia showing distribution of herbivorous intermediate hosts mapped and optimized on the parasite cladogram $(\mathrm{CI}=0.89 ; \mathrm{RI}=0.85 ; \mathrm{RC}=0.75)$. Intermediate hosts are represented by Rodentia $=$ Ro, Bovidae $=$ Bo, Cervidae $=$ $\mathrm{Ce}$, Suidae $=\mathrm{Su}$, Lagomorpha $($ Leporidae $)=\mathrm{La}$, Hyracoidea $($ Procaviidae $)=\mathrm{Hy}$, Canidae $=\mathrm{Ca}$ and Primates (including Hominidae $)=\operatorname{Pr}$. Patterns are consistent with stability in life history and transmission and relatively limited host-switching among rodent, leporid, and artiodactyl intermediates.

(2) based on the presence/absence of hooks, Taeniarhynchus, Fossor, and Monordotaenia. As Rausch $(1994,1997)$ has outlined, recognition of these genera would result in a number of often monotypic taxa, for many based solely on characteristics of the metacestodes. That these concepts for a diversity of discrete genera within Taenia are refuted is indicated by the phylogenetic relationships postulated for this group in which recognition of any of these would result in paraphyly for Taenia (Fig. 1).

Diagnosis for Group I and Group II within Taenia as proposed by Verster (1969) is equivocal. The relative position of the genital ducts and osmoregulatory canals (character 3) exhibits extensive parallelism and reversal within the genus; CI $=0.20$ for this character (Fig. 2).

Phylogenetic studies of the Cyclophyllidea indicate a close relationship for Taeniidae and Dasyurotaenia, but inclusion along with Anoplotaenia in the Taeniidae remains equivocal. For the latter, this contention appears to be refuted by the structure of the metacestode (Beveridge et al., 1975; Hoberg et al., 1999). The placement of Insinuarotaenia also remains ambiguous, pending description of metacestodes and elucidation of the life cycle (Rausch, 1994, 1997).

\section{Phylogeny and morphogenesis of metacestodes}

Asexual development and multiplication of metacestodes is widespread among species of Taenia (e.g., Freeman, 1956; 
Abuladze, 1964; Moore and Brooks, 1987); however, morphogenesis by proliferative budding leading to discrete cysticerci appears relatively rare and is observed primarily in $T$. crassiceps and T. polyacantha. Rausch and Fay (1988a, 1988b) indicated that morphogenesis by proliferative budding in early metacestodes of these species was independently derived. The close relationship postulated, however, suggests that such proliferative morphogenesis may be homologous. Interestingly, there are also reports of proliferative budding for $T$. pisiformis (Crusz, 1948; Opuni, 1970), placed in the T. acinonyxi subclade and as the sister species of $T$. serialis. In this situation, however, the transverse fission described for $T$. pisiformis does not appear homologous to the ontogeny of metacestodes in $T$. crassiceps or $T$. polyacantha nor to development of the coenurus and other polycephalic forms.

Polycephalic larvae (excluding the coenurus) are primarily characteristic of basal species in the genus, including $T$. mustelae, T. selousi, T. twitchelli, and T. endothoracicus. The diversity of proliferative forms, and their distribution among often phylogenetically unrelated species of Taenia is consistent with the contention by Moore and Brooks (1987) for multiple and independent origins of asexual reproduction.

Rausch (1981) postulated that the hemistrobilocercus larva of $T$. rileyi was intermediate in form to the strobilocercus and cysticercus. The relative relationships for T. taeniaeformis (possessing a strobilocercus), T. parva (polycephalic strobilocercus), and $T$. rileyi corroborate homology for development and structure of metacestodes (character 9) among these species.

\section{Parasite-host cospeciation}

Verster (1969) in recognizing 2 groups within Taenia postulated that Group I included those species in humans and all in canines and felids (except $T$. taeniaeformis); Group II included $T$. taeniaeformis in addition to those cestodes in mustelids and viverrids. Based on the current study, 2 groups of Taenia are not demonstrated, and basal species are represented broadly among mustelids, viverrids, felids, and canids (Fig. 3). Results of analyses by Moore and Brooks (1987), Okamoto et al. (1995), and De Queiroz and Alkire (1998) were largely incongruent with host relationships, refuting an hypothesis for extensive cospeciation between Taenia spp. and either their intermediate or definitive hosts.

Examined at the level of order or family for hosts, the results of the current study in part corroborate these latter conclusions. Coevolution (encompassing cospeciation and coadaptation; Brooks and McLennan, 1991; Hoberg et al., 1997) with respect to carnivorous definitive hosts and Taenia appears to be limited. Although felids are putative ancestral hosts, contemporary associations appear to have resulted from extensive host-switching among felids, canids, hyaenids, and others (Fig. 3).

In contrast, relationships with herbivorous intermediate hosts are indicative of more pervasive coevolution (Fig. 4). It is postulated that rodents as intermediate hosts were ancestral for the Taeniidae, Taenia + Echinococcus. This is also compatible with a sister-group relationship between the Taeniidae and the $\mathrm{Pa}$ ruterinidae + Metadilepididae (Hoberg et al., 1999). Basal intermediate hosts for species of Taenia are rodents and early diversification within the genus, except for $T$. macrocystis, appears associated with these mammals; acquisition of ruminant or lagomorph intermediates occurred independently (Fig. 4) and for the latter is represented by multiple events of colonization. Additionally, ruminants were independently colonized by both Taenia and Echinococcus subsequent to the divergence of these taxa. Minimally, artiodactyls (particularly bovids) may have been colonized once by Taenia (Fig. 4), but the occurrence of some cervids and suids as intermediate hosts may be explained by independent host-switching, e.g., $T$. parenchymatosa and $T$. omissa in cervids; $T$. hydatigena and $T$. ovis in bovids and cervids; $T$. solium and $T$. asiatica in suids; and $T$. acinonyxi and $T$. regis in suids.

We can further examine the putative relationships among Taenia and their hosts based on mapping and optimization of host taxa onto the parasite phylogeny (Figs. 3, 4). It is apparent that intermediate hosts $(\mathrm{CI}=0.89)$ are evolutionarily conservative for Taenia, in contrast to definitive hosts $(\mathrm{CI}=0.46)$ that appear to be more contingent. Acquisition of novel definitive hosts occurred more often in the evolution of this group in contrast to shifts among alternative intermediate hosts that are intimately involved in the maintenance of cycles. Life history then must be viewed as evolutionarily conservative with respect to diversification within this clade; host-switching occurred as a stochastic process but within the context of paleoguilds, or guilds, linked to specific trophic associations. Thus, shifts between definitive hosts were facilitated, whereas those between intermediate hosts were moderated, particularly if such would remove a parasite from a particular guild assemblage and result in a discontinuity in transmission (consider the contrasting micro- versus macroevolutionary implications).

We would predict that ecological stability and continuity is linked to intermediate hosts and transmission dynamics in this assemblage, which is otherwise driven and defined by predatorprey associations. This suggests that selection is for continuity in transmission rather than for association with a particular definitive host group. Consequently, speciation is likely to be driven by definitive hosts, whereas ecological continuity and predictability are limited by transmission dynamics linked to the intermediate hosts (Hoberg et al., 1999). This observation and prediction parallels that developed for patterns and processes of speciation within the marine assemblage represented by tetrabothriid cestodes of the genus Anophryocephalus and their pinniped hosts (see Hoberg, 1992, 1995, 1997).

These observations are compatible with relatively low levels of apparent cospeciation between Taenia and their definitive hosts, e.g., in mustelids, in some hyaenids, and possibly to a limited extent among some large felids, canids, and humans (Fig. 3). Otherwise, patterns appear consistent with rapid shifts between phylogenetically unrelated carnivores but among those that historically exploited a common prey resource in communities that occupied a specific biogeographic region. Such is particularly evident with respect to the distribution of Taenia spp. among large felids, hyaenids, some canids, and humans in Africa, e.g., T. madoquae, T. gonyamai, T. crocutae, T. hyaenae, and $T$. solium.

As adults, species of Taenia are characteristic parasites in carnivore definitive hosts; only 3 species ( $T$. saginata, $T$. asiatica, and T. solium) occur in humans (Eom and Rim, 1993; Bowles and McManus, 1994; Fan et al., 1995). Consistent with De Queiroz and Alkire (1998), results of the current analysis 
indicate that $T$. saginata $+T$. asiatica are putative sister species and that they are distantly related to $T$. solium (Fig. 1).

Although these species may be of substantial economic significance (e.g., Fan and Chung, 1995), there have been few prior hypotheses for the relationships of Taenia spp. in humans. Origins of Taenia in humans were considered to have been coincidental with the domestication of bovid and suid hosts and colonization of humans by cestodes associated with companion carnivores in which a synanthropic cycle was characteristic (conventional wisdom outlined by Cameron [1956]). Baer (1940), however, articulated a more detailed hypothesis for the relationships of these species. He considered that $T$. saginata and $T$. solium were not closely related and had been acquired by humans via colonization along 2 separate routes. For $T$. solium, this would have predated the domestication of suid hosts, with colonization of hominids by a Taenia possibly circulating in wild suids such as warthogs (Phacochoerus aethiopicus [Pallas]) or bush pigs (Potamochoerus porcus [Linnaeus]) and large felids. Secondarily, synanthropic maintenance of this association would have involved human definitive and canid and suid intermediate hosts, including Sus scrofa Linnaeus. In contrast, the origin of $T$. saginata was linked to domestication of bovids by modern humans. This latter point is of interest with respect to the putative dates of domestication for bovids and cattle in particular at a minimum of $8,000-10,000 \mathrm{yr}$, and the possibility of independent centers of domestication for cattle of Asia, Europe, and Africa that could be substantially older (Epstein and Mason, 1984; Bradley et al., 1996). Hypotheses for the diversification of Taenia spp. in human hosts will be examined in detail elsewhere.

Species of Taenia are important parasites and pathogens and have considerable veterinary and medical significance (Abuladze, 1964; Rausch, 1994, 1997). Knowledge of phylogenetic relationships for this complex genus will enhance our ability to predict and understand life history, geographic distribution, and the zoonotic potential for a diversity of species. Although deferred to a future analysis, resolution of the coevolutionary and biogeographic history for this assemblage will result from: (1) refinement of this initial hypothesis for phylogeny of Taenia; (2) a phylogenetic context for relationships of families and genera of terrestrial mammals serving as intermediate and definitive hosts; and (3) examination of the geographic ranges for the diversity of Taenia spp.

\section{ACKNOWLEDGMENTS}

This is a contribution from the 2nd International Workshop for Tapeworm Systematics (IWTS), organized by E. P. Hoberg, S. L. Gardner, and R. L. Campbell and held at the University of Nebraska-Lincoln on 2-6 October 1996. The current paper, represents subsequent analyses by Taenia Working Group. Conceptual issues about host-parasite evolution were focused through discussion with Daniel Brooks, University of Toronto, and Alan de Queiroz and Nancy Alkire, University of Colorado.

\section{LITERATURE CITED}

AbuladZe, K. I. 1964. Essentials of cestodology, Vol. IV. Taeniata of animals and man and diseases caused by them. Akademiia Nauk SSSR, Gel'mintologicheskaia Laboratoriia, Izdatel'stvo Nauka, Moskva. [English translation, 1970, Israel Program for Scientific Translations, Jerusalem, 549 p.]
BAER, J. G. 1940. The origin of human tapeworms. Journal of Parasitology 26: 127-134.

Bessonov, A. S., S. O. Movsessian, and K. I. Abuldaze. 1994. On the classification and validity of superspecies taxons of the cestodes of the superorder Taeniata Skrjabin et Schulz, 1937. Helminthologia 31: $61-71$.

Beveridge, I., M. D. Richard, G. G. Gregory, and B. L. Mundy. 1975. Studies on Anoplotaenia dasyuri Beddard, 1911 (Cestoda: Taeniidae), a parasite of the Tasmanian devil: Observations on the egg and metacestode. International Journal for Parasitology 5: 257-267.

Bowles, J., AND D. P. MCMANus. 1994. Genetic characterization of the Asian Taenia, a newly described taeniid tapeworm of humans American Journal of Tropical Medicine and Hygiene 50: 33-44.

Bradley, D. G., D. E. MacHugh, P. Cunningham, and R. T. Loftus 1996. Mitochondrial diversity and the origins of African and European cattle. Proceedings of the National Academy of Sciences USA 93: 5131-5135.

Brooks, D. R., E. P. Hoberg, and P. J. Weekes. 1991. Preliminary phylogenetic analysis of the major lineages of the Eucestoda (Platyhelminthes: Cercomeria). Proceedings of the Biological Society of Washington 104: 651-668.

- AND D. A. MCLENNAN. 1991. Phylogeny, ecology and behavior a research program in comparative biology. University of Chicago Press, Chicago, Illinois, $434 \mathrm{p}$.

- AND - 1993. Parascript. Parasites and the language of evolution. Smithsonian Institution Press, Washington, D.C., 429 p.

Cameron, T. W. M. 1956. Parasites and parasitism. John Wiley and Sons, New York, New York, 322 p.

Crusz, H. 1948. On the transverse fission of Cysticercus pisiformis in experimentally infested rabbits and the phylogenetic significance of asexual phenomena in cysticerci. Journal of Helminthology 22: $165-178$.

DeQueiroz, A., And N. Alkire. 1998. The phylogenetic placement of Taenia cestodes that parasitize humans. Journal of Parasitology 84: 379-383.

DinNiK, J. A., AND R. SACHS. 1969. Zystizerkose der Kreuzbeinwirbel bei Antilopen und Taenia olngojinei sp. nov. der Tüpfelhyäne. Zeitschrift für Parasitenkunde 31: 326-339.

, AND - 1972. Taeniidae of lions in East Africa. Zeitschrift für Tropenmedizin und Parasitologie 23: 197-210.

EOM, K. S., AND H.-J. RIM. 1993. Morphological description of Taenia asiatica sp. n. Korean Journal of Parasitology 31: 1-6.

Epstein, H., AND I. L. MASON. 1984. Cattle. In Evolution of domesticated animals, I. L. Mason (ed.). Longman Inc., New York, New York, p. 6-27.

Fan, P. C., AND W. C. Chung. 1995. Annual economic loss due to taeniasis among aborigines in Taiwan. Yonsei Reports on Tropical Medicine 26: 19-24.

- C. Y. Lin, C. C. CHEN, AND W. C. ChUNG. 1995. Morphological description of Taenia saginata asiatica (Cyclophyllidea: Taeniidae) from man in Asia. Journal of Helminthology 69: 299-303.

FreemAN, R. 1956. Life history studies on Taenia mustelae Gmelin, 1790 and the taxonomy of certain taenioid cestodes from Mustelidae. Canadian Journal of Zoology 34: 219-242.

- 1959. On the taxonomy of the genus Cladotaenia, the life histories of $C$. globifera (Batsch, 1786) and C. circi Yamaguti, 1935, and a note on distinguishing between the plerocercoids of the genera Paruterina and Cladotaenia. Canadian Journal of Zoology 37: 317-340.

GUBÁNYI, A. 1995. Morphometrics of taeniid tapeworms I. Multivariate analysis of distance measurements of the rostellar hooks. Parasitologica Hungarica 28: 21-41.

HenNig, W. 1966. Phylogenetic systematics. University of Illinois Press, Urbana, Illinois, $263 \mathrm{p}$.

HOBERG, E. P. 1992. Congruent and synchronic patterns in biogeography and speciation among seabirds, pinnipeds, and cestodes. Journal of Parasitology 78: 601-615.

- 1995. Historical biogeography and modes of speciation across high latitude seas of the Holarctic: Concepts for host-parasite coevolution among the Phocini (Phocidae) and Tetrabothriidae (Eucestoda). Canadian Journal of Zoology 73: 45-57.

- 1997. Phylogeny and historical reconstruction: Host- parasite systems as keystones in biogeography and ecology. In Biodiversity 
II: Understanding and protecting our biological resources, M. L. Reaka-Kudla, D. E. Wilson, and E. O. Wilson (eds.). Joseph Henry Press, Washington, D.C., p. 243-261.

, D. R. BROoKS, and D. Siegel-Causey. 1997. Host-parasite cospeciation: History, principles and prospects. In Host-parasite evolution, general principles and avian models, D. H. Clayton and J. Moore (eds.). Oxford University Press, Oxford, U.K., p. 212 235.

, A. Jones, AND R. BRay. 1999. Phylogenetic analysis among the families of the Cyclophyllidea (Eucestoda) based on comparative morphology, with new hypotheses for co-evolution in vertebrates. Systematic Parasitology 42: 51-73.

Jones, A., B. A. Allsop, C. N. L. Macpherson, ANd M. T. E. P. Allsop. 1988. The identity, life-cycle and isoenzyme characteristics of Taenia madoquae (Pellegrini, 1950) n. comb. from silver-backed jackal (Canis mesomelas Schreber, 1775) in East Africa. Systematic Parasitology 11: 31-38.

— AND L. F. KhaliL. 1984. Taenia dinniki sp. nov. (Cestoda: Taeniidae) from the striped and spotted hyaena in East Africa. Journal of Natural History 18: 803-809.

Kornet, D. J., AND H. TURNER. 1999. Coding polymorphism for phylogenetic reconstruction. Systematic Biology 48: 365-379.

Korniushin, V. V., AND L. D. Sharpilo. 1986. Novyi rod teniid (Cestoda: Taeniidae)-parazitov kun'ikh. Vestnikh Zoologii 3: 10-16.

Maddison, W. P., M. J. Donoghue, And D. R. Maddison. 1984. Outgroup analysis and parsimony. Systematic Zoology 33: 83-103.

- , AND D. R. MADDISON. 1992. MacClade: Analysis of phylogeny and character evolution, version 3.05. Sinauer Associates, Sunderland, Massachusetts.

MOORE, J., AND D. R. Brooks. 1987. Asexual reproduction in cestodes (Cyclophyllidea: Taeniidae): Ecological and phylogenetic influences. Evolution 41: 882-891.

Movsessian, S. O. 1989. Present views on the systematics of cestodes of the suborder Taeniata. Helminthologia 26: 3-14.

Murai, É., A. GubánYi, ANd L. Sugár. 1993. Examination of taeniid metacestodes from the Far East, with the description of Taenia kotlani sp. n. (Cestoda: Taeniidae). Parasitologica Hunagarica 26: 27-49.

, F. Tenora, And M. Stanek. 1989. Atypical strobilocercus (Cestoda: Taeniidae), a parasite in experimental stocks of Ondatra zibethicus (Rodentia). Miscellanea Zoologica Hungarica 5: 21-27.

OKamoto, M., Y. Bessho, M. Kamiya, T. Kurosawa, and T. Horil. 1995. Phylogenetic relationships within Taenia taeniaeformis variants and other taeniid cestodes inferred from nucleotide sequence of the cytochrome $c$ oxidase subunit I gen. Parasitology Research 81: $451-458$.
OPUNI, E. K. 1970. Asexual multiplication in Cysticercus pisiformis (Cestoda). Journal of Helminthology 44: 321-322.

Pimentel, R. A., AND R. Riggins. 1987. The nature of cladistic data. Cladistics 3: 201-209.

RausCH, R. L. 1977. The specific distinction of Taenia twitchelli Schwartz, 1924 from T. martis (Zeder, 1803) (Cestoda: Taeniidae). Excerta parasitológica en memoria del Doctor Eduardo Caballero y Caballero. Instituto de Biología, Universidad Nacional Autónoma de México. Publicaciones Especiales (México) 4: 357-366.

. 1981. Morphological and biological characteristics of Taenia rileyi Loewen, 1929 (Cestoda: Taeniidae). Canadian Journal of Zoology 59: 653-666.

- 1994. Family Taeniidae Ludwig, 1886. In Keys to the cestode parasites of vertebrates, L. F. Khail, A. Jones, and R. Bray (eds.) International Institute of Parasitology, Commonwealth Agricultural Bureaux, Wallingford, U.K., p. 665-672.

- 1997. Echinococcus granulosus: Biology and ecology. In Compendium on cystic echinococcosis in Africa and in middle eastern countries with special reference to Morocco, F. L. Andersen, H Ouhelli, and M. Kachani (eds.). Brigham Young University Press, Provo, Utah, p. 18-53.

, AND F. H. FAY. 1988a. Postoncospheral development and cycle of Taenia polyacantha Leuckart, 1856 (Cestoda: Taeniidae). First part. Annales de Parasitologie Humaine et Comparée 63: 263-277.

, AND - 1988b. Postoncospheral development and cycle of Taenia polyacantha Leuckart, 1856 (Cestoda: Taeniidae). Second part. Annales de Parasitologie Humaine et Comparée 63: 334 348.

SACHS, R. 1969. Untersuchungen zur Artbestimmung und Differenzierung der Muskelfinnen ostafrikanischer Wildtiere. Zeitschrift fü Tropenmedizin und Parasitologie 20: 39-50.

SCHMIDT, G. D. 1986. Handbook of tapeworm identification. CRC Press, Boca Raton, Florida, 675 p.

SpASSKII, A. A. 1998. O taksonomii teniid (Cestoda: Cyclophyllidea) In The problems of cestodology. Scientific Works, St. Petersburg, Russia, p. 129-135.

SwOFFORD, D. 1993. Phylogenetic analysis using parsimony (PAUP), Version 3.1.1. Computer program. Illinois Natural History Survey, Champaign, Illinois.

- AND D. P. BEGLE. 1993. Users manual: Phylogenetic analysis using parsimony, Version 3.1.1. Smithsonian Institution, Washington, D.C., 257 p.

Verster, A. 1969. A taxonomic revision of the genus Taenia Linnaeus, 1758 s. str. Onderstepoort Journal of Veterinary Research 36: 358 .

Watrous, L. E., AND Q. D. WheELER. 1981. The outgroup comparison method of character analysis. Systematic Zoology 30: 1-11. 